\title{
HUBUNGAN PENGETAHUAN TENTANG SEKSUAL DENGAN ANTISIPASI TERHADAP RISIKO KEKERASAN SEKSUAL PADA REMAJA
}

\author{
Rina Delfina ${ }^{1}$, Nurmukaromatis Saleha ${ }^{2}$, Sardaniah Sardaniah ${ }^{3}$, Nurlaili Nurlaili ${ }^{4}$ \\ 1,2,3,4 Program Studi D3 Keperawatan, Universitas Bengkulu, Indonesia \\ rdelfina@unib.ac.id
}

\begin{abstract}
ABSTRAK
Tingginya kasus eksploitasi seksual dan perdagangan anak melalui media online yang marak terjadi akhir-akhir ini dapat dijadikan tanda bagi orang tua dan masyarakat untuk mengoptimalkan upaya agar remaja terhindar dari risiko kekerasan seksual. Kejahatan seksual yang terjadi baik melalui media online maupun tidak merupakan kejahatan yang harus diperangi bersama. Namun, survei tentang kekerasan seksual yang terjadi pada anak dan remaja tahun 2018 menunjukkan masih ada. Tujuan penelitian ini adalah untuk melihat hubungan pengetahuan dengan antisipatisi terhadap risiko kekerasan seksual pada remaja. Desain penelitian ini adalah penelitian kuantitatif dengan Pendekatan Cross Sectional. Pengambilan sampel menggunakan rumus estimasi proporsi dengan jumlah sampel 319 remaja putri. Analisis data yang digunakan adalah Uji Chi-Square. Hasil penelitian menunjukkan ada hubungan yang bermakna antara pengetahuan tentang seksual dengan antisipasi terhadap risiko kekerasan seksual pada remaja dengan ( $p$-value: 0,000$)$. Pengetahuan yang baik tentang seksual sangat penting bagi remaja agar terhindar dari risiko kekerasan seksual. Remaja disarankan untuk tetap waspada dan jangan takut untuk melaporkan segera kepada orang tua, guru, dan polisi sehingga terhindar dari dampak negatif kekerasan seksual.
\end{abstract}

Kata kunci : kekerasan seksual, pengetahuan, remaja

\section{THE RELATIONSHIP BETWEEN KNOWLEDGE ABOUT SEXUALS AND ANTICIPATION OF THE RISK OF SEXUAL VIOLENCE IN ADOLESCENTS}

\section{ABSTRACT}

The high number of cases of sexual exploitation and child trafficking through online media that has been rampant lately can be a sign for parents and the public in optimizing efforts so that adolescents can avoid the risk of sexual violence. Sexual crimes that occur either through online media or not are crimes that must fight together. The survey on sexual violence that occurred in children and adolescents in 2018 shows that it is still. The purpose of this study was to examine the relationship between knowledge and anticipation on the risk of sexual violence in adolescents. The design of this study is a quantitative study with a cross-sectional approach. The sample takes using a proportion estimation formula with a total sample size of 319 young women. The data analysis used was Chi-Square. The results showed a significant relationship between knowledge about sexuality with the anticipation of the risk of sexual violence in adolescents (p-value: 0.000). A good understanding of sexuality is essential for adolescents to avoid the risk of sexual violence. It is recommended for adolescents to remain vigilant and not afraid to report immediately to parents, teachers, and the police so that adolescents avoid the negative impacts of sexual violence.

Keywords: adolescents, knowledge, sexual violence 


\section{PENDAHULUAN}

Remaja adalah masa transisi dengan perubahan dari masa anak-anak ke masa dewasa. Remaja cenderung mengalami perubahan baik secarafisik maupun psikologis yang memengaruhi perkembangan pada dirinya (Wong D. L., 2013). Remaja menurut Badan Kependudukan dan Keluarga Berencana (BKKBN) adalah seseorang yang belum menikah dengan rentang usia antara 10 sampai dengan 24 tahun. Perbedaan tersebut menunjukkan tidak ada kesepakatan universal mengenai batasan kelompok usia remaja, namun tetap diasosiasikan sama sebagai masa transisi. Masa remaja merupakan masa mulai membangun identitas, akuisisi kemampuan serta mampu untuk bernegosiasi, serta matang secara fisik, seksual, kemandirian sosial dan ekonomi.

Data demografi dunia memberikan prediksi terhadap kondisi kependudukan di Indonesia bahwasanya akan terjadi ledakan penduduk usia remaja pada tahun 2020-2030. Mengingat hal tersebut sangat penting bagi kita untuk menjaga kualitas remaja agar dapat menikmati bonus demografi sebagai aset negara (Kusumaryani, 2017).

Memasuki masa pubertas atau masa remaja terjadi puncak perkembangan seksual. Pertumbuhan identitas sekunder semakin jelas untuk membedakan diantara dua jenis kelamin. Selain itu, remaja juga mengalami gejolak emosional yang sebanding dengan perubahan fisik yang dialaminya. Perubahan fisik dan seksual berlangsung sangat signifikan pada masa remaja. Hal ini menjadi pemicu dorongan seksual dan ketertarikan seksual pada lawan jenis. Faktor lingkungan sebagai faktor eksternal merupakan faktor yang banyak memengaruhi perkembangan seksual individu (Afiyanti, Y., \& Pratiwi, A., 2017).

Remaja belajar menerima perbedaan dirinya dengan individu lain baik secara fisik maupun ideologi dan beradaptasi terhadap perubahan yang terjadi pada dirinya. Tahapan inilah yang disebut oleh Erikson sebagai identitas versus kebingungan identitas. Kematangan fisik dan seksual pada remaja tidak diimbangi dengan kemampuan mereka bertanggung jawab dalam seksualitas sehingga bukanlah fenomena yang baru jika kita melihat remaja menjadi orang tua, secara alamiah perempuan mulai mampu untuk melahirkan pada masa remaja dan awal usia dua puluhan (Adebayo, O., \& Isiakpona, 2012). Kondisi tersebut menjadikan remaja rawan terhadap permasalahan kesehatan terutama kesehatan reproduksi seperti seks bebas yang dapat mengakibatkan kehamilan pra nikah yang mengakibatkan akan meningkatnya upaya untuk menggugurkan kehamilan tersebut, meningkatnya penyakit menular seksual (PMS), HIV-AIDS, serta penggunaan obat-obat terlarang, yang sering terjadi pada remaja. Tiga masalah kesehatan reproduksi remaja tersebut (seksualitas, Napza dan HIV-AIDS) dikenal dengan Triad KRR (BKKBN, 2012).

Kekerasan seksual merupakan salah satu masalah yang sering muncul pada remaja. Kekerasan seksual adalah segala bentuk kekerasan yang dapat menimbulkan masalah secara fisik maupun psikologis pada anak sehingga dapat mengancam jiwanya (Sugijokanto, 2014). Kekerasan seksual pada anak dapat dilakukan oleh siapa saja, baik oleh orang terdekat maupun orang lain yang tidak dikenal. Banyak masalah yang muncul akibat kekerasan seksual yang dialami anak atau remaja seperti rasa trauma, depresi, bahkan keinginan untuk bunuh diri.. Faktor-faktor yang dapat menyebabkan kekerasan seksual, meliputi faktor genetik dan faktor lingkungan (Madani, 2014). Untuk mengurangi risiko kekerasan seksual maka remaja harus memiliki pengetahuan yang baik tentang seksual. Pengetahuan tentang seks dapat dimulai dari usia dini. Dalam menjalankan pendidikan seks harus mengacu pada nilai- 
nilai yang dianut, guru pun harus menjalankan peran secara optimal dalam mengintegrasikan nilai-nilai baik secara implisit maupun eksplisit untuk mengemukakan bahwasanya bicara seks adalah wajar, dibenarkan dan demi kepentingan peserta didik (Francis, 2013). Dari sistem nilai yang dianut oleh guru, orang tua dan masyarakat inilah timbul dilema dalam mengaplikasikan pendidikan seks di sekolah. Tujuan penelitian ini melihat hubungan pengetahuan tentang seksual dengan antisipasi kekerasan seksual pada remaja.

\section{METODOLOGI}

Desain penelitianinimerupakanpenelitian kuantitatif dengan Pendekatan Cross Sectional. Populasi pada penelitian ini adalah remaja di Kota Bengkulu. Jumlah sampel dalam penelitian ini adalah 319 orang. Teknik pengambilan sampel menggunakan rumus estimasi proporsi. Instrumen penelitian menggunakan kuesioner yang disebarkan melalui google form yang langsung dikirimkan ke responden. Analisis data pada penelitian ini menggunakan uji statistik chi-square. Penelitian ini sudah melewati tahap uji etik penelitian pada komite etik fakultas kedokteran Universitas Bengkulu Nomor: 278/ UN30.14.9//LT/2020 tanggal 24 September 2020 .

\section{HASIL}

Distribusi frekuensi karakteristik responden dapat dilihat pada tabel 1. Rata-rata usia responden 16 tahun, dengan usia minimal 13 tahun dan usia maksimal 24 tahun dari 319 responden.

Tabel 1. Karakteristik Responden Berdasarkan Usia

\begin{tabular}{lcccc}
\hline Variabel & Mean & Median & SD & Min-Maks \\
\hline Usia & 16,09 & 15,00 & 1,824 & $13-24$ \\
\hline
\end{tabular}

Tabel 2. Karakteristik Responden Berdasarkan Tingkat Pendidikan

\begin{tabular}{lcc}
\hline Pendidikan & $\mathbf{n}$ & $\mathbf{\%}$ \\
\hline SMP & 6 & $1,9 \%$ \\
SLTA & 243 & $73,4 \%$ \\
PT & 79 & $24,8 \%$ \\
\hline Total & $\mathbf{3 1 9}$ & $\mathbf{1 0 0 \%}$ \\
\hline
\end{tabular}

Tabel 3. Hubungan Pengetahuan Seksual Dengan Antisipasi Terhadap Risiko Kekerasan Seksual

\begin{tabular}{|c|c|c|c|c|c|c|}
\hline \multirow{3}{*}{ Pengetahuan } & \multicolumn{4}{|c|}{ Antisipasi Kekerasan seksual } & \multirow{3}{*}{ Total } & \multirow{3}{*}{ p-value } \\
\hline & \multicolumn{2}{|c|}{ Buruk } & \multicolumn{2}{|c|}{ Baik } & & \\
\hline & $\mathbf{n}$ & $\%$ & n & $\%$ & & \\
\hline Kurang & 73 & $32,7 \%$ & 150 & $67,2 \%$ & 223 & \multirow{2}{*}{0,000} \\
\hline Baik & 6 & $6,25 \%$ & 90 & $93,7 \%$ & 96 & \\
\hline Total & 79 & & 240 & & 319 & \\
\hline
\end{tabular}

Berdasarkan tabel 3 menunjukkan bahwa dari 223 responden yang berpengetahuan kurang terdapat $73(32,3 \%)$ responden memiliki antisipasi buruk dan $150(67,2 \%)$ responden memiliki antisipasi baik terhadap risiko kekerasan seksual. Sedangkan dari 96 responden yang memiliki pengetahuan baik, terdapat 6 $(6,25 \%)$ responden memiliki antisipasi buruk 
dan $90(93,7 \%)$ responden memiliki antisipasi baik terhadap risiko kekerasan seksual. Hasil uji statistik menunjukkan $P$ value $=0,000<\alpha(0,05)$ dapat disimpulkan bahwa ada hubungan yang bermakna antara pengetahuan tentang seksual dengan antisipasi terhadap risiko kekerasan seksual pada remaja di Kota Bengkulu.

\section{PEMBAHASAN}

\section{Karakteristik Responden}

Karakteristik responden pada penelitian ini berdasarkan usia rata-rata 16 tahun, usia tertinggi 24 tahun dan 13 tahun usia terkecil. Menurut Krori (2011) menjelaskan bahwa masa remaja merupakan bagian dari siklus kehidupan manusia dimana terjadi perubahan dari masa anak-anak ke masa dewasa. Jika masa remaja bisa dilewati dengan baik maka akan menimbulkan kepercayaan diri dalam menghadapi masa depan selanjutnya. Berdasarkan hasil penelitian menunjukkan bahwa remaja akhir yang berusia antara 16-18 tahun memiliki pengetahuan yang lebih baik dibandingkan dengan remaja awal yang berusia antara 13-15 tahun, Individu akan mencapai tingkat kematangan pada saat memasuki masa remaja akhir yang mendekati masa dewasa. Usia yang lebih matang dapat memahami informasi yang diperoleh secara langsung maupun media massa tentang seksual dan dijadikan benteng untuk pertahanan diri terhadap risiko kekerasan seksual.

Berdasarkan hasil penelitian sebagian besar pendidikan responden adalah SLTA $243(73,4 \%)$. Tingkat pendidikan mendorong seseorang untukmemperoleh informasi yang lebih lengkap terhadap sesuatu. Tingkat pendidikan remaja juga mempengaruhi dalam pengambilan sikap dan tindakan terhadap antisipasi risiko kekerasan seksual. Pendidikan yang dimiliki oleh responden sangat mempengaruhi dalam menerima berbagai informasi dari berbagai media khususnya tentang kekerasan seksual pada remaja. Tingkat pendidikan seseorang sangat mempengaruhi kecerdasan dan tingkat pengetahuan sertapemahaman seseorang terhadap suatu pembahasan menurut (Widyawati, 2016). Pendidikan adalah suatu usaha menanamkan pengertian dan tujuan agar pada diri manusia (masyarakat) tumbuh pengertian, sikap dan perbuatan positif (Notoatmodjo, 2012).

\section{Hubungan Pengetahuan Tentang Seksual dengan Antisipasi Terhadap Risiko Kekerasan Seksual pada Remaja}

Hasil penelitian menunjukkan bahwa responden yang memiliki pengetahuan baik tentang seksual lebih memiliki antisipasi yang baik terhadap risiko kekerasan seksual. Hal ini menunjukkan bahwa pengetahuan tentang seksual akan membantu remaja dalam mengenali tanda-tanda kekerasan seksual atau pelecehan terhadap dirinya, dan upaya apa yang akan dilakukan jika menghadapi hal tersebut dalam kehidupan sehari-hari. Pengetahuan muncul ketika seseorang menggunakan indra atau akal budinya untuk mengenali benda atau kejadian tertentu yang belum pernah dilihat untuk mengenali benda atau kejadian tertentu yang belum pernah dilihat atau dirasakan sebelumnya (Notoatmodjo, 2012). Adanya pengaruh yang kuat dari variabel yang lain seperti sumber informasi yang dapat mempengaruhi remaja dalam antisipasi terhadap risiko kekerasan seksual. Pengetahuan tentang seksual dapat diperoleh remaja melalui pendidikan formal maupun informal baik dari media massa, televisi dan lain-lain. Pendidikan Seks yang diberikan secara seimbang antara pendekatan pengetahuan biologis dan pendekatan sosiologis diharapkan bermanfaat bagi para remaja dan dapat membantu para remaja dalam mengambil keputusan yang baik dalam kehidupannya. Pentingnya pendidikan seks diberikan pada remaja karena dengan pendidikan seks yang 
tepat mampu menyelamatkan kaum remaja dari keadaan yang tidak sehat atau berbahaya untuk kesehatannya. Seharusnya Pendidikan Seks tidak dianggap tabu dan tidak ditutupi lagi. Pendidikan seksualitas dan reproduksi penting bagi setiap individu dikarenakan keduanya dapat menjadi penentu status kesehatan secara umum (overall health) dan kualitas hidup (quality of life) individu. Bahkan permasalahan seksualitas dapat menjadi penyebab secara tidak langsung dari kematian (Afiyanti, Y., \& Pratiwi, A., 2017). Seharusnya Pendidikan Seks tidak dianggap tabu dan tidak ditutupi lagi. Pengetahuan yang baik tentang seksual dapat mempengaruhi seseorang dalam bersikap dan bertindak terhadap apa yang dialaminya.

Berdasarkan hasil penelitian ini dapat dilihat bahwa pengetahuan remaja berbanding lurus dengan antisipasi terhadap risiko kekerasan seksual pada remaja. Pengetahuan dapat diperoleh melalui pendidikan karena pendidikan merupakan domain yang sangat penting, semakin tinggi jenjang pendidikan maka akan memperluas atau mendukung pengetahuan yang diperoleh remaja tentang sesuatu. Namun, perlu ditekankan bahwa seseorang dengan pendidikan tinggi belum tentu mutlak memiliki pengetahuan yang baik tentang sesuatu. (Fisnawati.S, Indriati G. \& Elita, V., 2016) menyebutkan bahwa pengetahuan yang didapat oleh remaja bisa secara internal maupun eksternal. Kurangnya pengetahuan remaja dan informasi menjadi faktor utama untuk terjadinya kekerasan seksual pada remaja. Hal ini didukung oleh penelitian Anindyajati (2013) bahwa faktor yang dapat memengaruhi risiko terjadinya kekerasan seksual pada remaja, karena kurangnya pengetahuan remaja meliputi pengertian, jenis, dan tanda gejala kekerasan seksual pada remaja. Remaja wajib dibekali pengetahuan untuk mencegah tindak kekerasan seksual. Pelecehan seksual yang dialami oleh remaja dapat terjadi pada remaja wanita dan laki-laki, pelecehan tersebut dapat berupa pelecehan fisik, dan pelecehan verbal (Edwfar, 2012), Kekerasan seksual bisa terjadi di sekolah, rumah dan lokasi lainnya. Hasil penelitian (Handayani et al., 2017) melaporkan bahwa komunikasi antara orang tua dan anak sangat diperlukan untuk menghindari perilaku kekerasan seksual. Kekerasan seksual berdampak besar pada kesehatan fisik dan mental. Serta menyebabkan cedera fisik, itu terkait dengan peningkatan risiko berbagai kesehatan seksual dan masalah reproduksi, yang muncul saat ini dan jangka panjang. Dampaknya pada kesehatan mental bisa sama seriusnya dengan dampak fisiknya, dan mungkin akan berlangsung lama, dampak jangka panjang kekerasan seksual terhadap anak yaitu anak yang menjadi korban kekerasan seksual pada masa kanak-kanak memiliki potensi untuk menjadi pelaku kekerasan seksual dikemudian hari (Weber, Mark Reese., Smith, 2010). Kekerasan seksual dapat terjadi dimana saja, bagi remaja yang masih sekolah risiko kekerasan dapat terjadi di lingkungan sekolah dan orang-orang yang berada didekat remaja. Hasil penelitian (Peni Wahyu Agustina, 2018) menunjukkan bahwa semua pelaku kekerasan seksual kepada korban adalah orang terdekat korban. Dua orang di antara pelaku masih memiliki hubungan kekeluargaan dengan korban. Sedangkan yang lainnya merupakan orang yang dekat dengan korban walaupun bukan keluarga. Keluarga yang seharusnya menjaga anak tersebut tidak disangka dapat menjadi pelaku kekerasan seksual. Sedangkan guru sebagai pengganti orang tua selama belajar dan menjadi panutan murid-muridnya malah menjadi predator bagi anak didiknya sendiri. Seorang teman tega menjadi pelaku kekerasan seksual terhadap temannya sendiri. Dari Laporan oleh Africa Rights menemukan kasus guru sekolah yang mencoba berhubungan seks dengan siswa dengan mengiming-imingi siswa dengan nilai yang bagus 


\section{SIMPULAN DAN SARAN}

Berdasarkan hasil penelitian dapat disimpulkan ada hubungan antara pengetahuan tentang seksual dengan antisipasi terhadap risiko kekerasan seksual pada remaja di Kota Bengkulu. Remaja disarankan untuk tetap waspada dan jangan takut untuk melaporkan segera kepada orang tua, guru dan polisi, sehingga remaja terhindar dari dampak negatif dari kekerasan seksual.

\section{DAFTAR PUSTAKA}

Adebayo, O., \& Isiakpona, C. D. (2012) 'The role of libraries in curbing teenage pregnancy in nigeria', Gender \& Behaviour, 10(1), pp. 4470-4479. Available at: http:// search.proquest.com/docview/10175402 69? accountid $=17242$.

Afiyanti, Y., \& Pratiwi, A. (2017) Seksualitas Dan Kesehatan Reproduksi Perempuan. Promosi, Permasalahan dan Penanganan dalam Pelayanan Kesehatan dan Keperawatan. PT Rajagrafindo Persada, Depok.

Anindyajati, P. . (2013) 'Status Identitas Remaja Akhir: Hubungannya dengan Gaya Pengasuhan Orang Tua Dan Tingkat Kenakalan Remaja', Universitas Negeri Surabaya, 1(2).

BKKBN. (2012). Pedoman Pengelolaan Pusat Informasi dan Konseling Remaja dan Mahasiswa (PIK Remaja/Mahasiswa). BKKBN, Jakarta

Edwfar (2012) 'kekerasan seksual pada anak meningkat'. Available at: http: // balikpapan. Prokal.co / read / news / 123955 .

Fisnawati.S, Indriati G. \& Elita, V. (2016) 'Hubungan Pengetahuan Dan Sikap Orang Tua Tentang Kesehatan Seksual Pada anak usia 7-12 tahun Dalam Pencegahan Kekerasan Seksual', Jurnal
Online Mahasiswa (JOM) Bidang ilmu Keperawatan, 2, pp. 638-646.

Francis, D. (2013) 'Sexuality education in south africa: Whose values are we teaching?', The Canadian Journal of Human Sexuality, 22(2), pp. 69-76. Available at: http://search.proquest.com/docview/145 9650430 ? accountid $=17242$.

Handayani, M. et al. (2017) 'Pencegahan Kasus Kekerasan Seksual Pada Anak Melalui Prevention of Sexual Violence Cases in Children Through Interpersonal Communication', Jurnal Ilmiah VISI PGTK PAUD dan DIKMAS, 12(1), pp. 67-80. Available at: journal. unj.ac.id/unj/index.php/jiv/article/ download/2805/2091.

Krori, S. D. (2011) 'Developmental Psychology', Homeopathic Journal, 4(3 Jan 2011). Available at: http://www.homeorizon. com/homeopathic-articles/psychology/ developmental-psychology.

Kusumaryani, M. (2017) Prioritaskan Kesehatan reproduksi remaja untuk menikmati bonus demografi. Lembaga Demografi FEB UI.

Madani, Y. (2014) Pendidikan Seks Usia Dini Bagi Anak Muslim. Jakarta: Zahra Publishing House.

Notoatmodjo, S. (2012) Promosi Kesehatan dan Perilaku Kesehatan. Jakarta: Rineka Cipta.

Peni Wahyu Agustina, A. K. R. (2018) 'ANALISIS TINDAK KEKERASAN SEKSUAL PADA ANAK SEKOLAH DASAR', Ilmu Pendidikan: Jurnal Kajian Teori dan Praktik Kependidikan, 3(2), pp. 151-15.

Sugijokanto, S. (2014) Cegah Kekerasan Pada Anak. Jakarta: PT. Elex Media Komputindo.

Weber, Mark Reese., Smith, D. M. (2010) 'Outcomes of Child Sexual Abuse as 
Predictors of laters Sexual Victimization', Journal of International Violence. (Online), 26(9), pp. 1899-1905.

Widyawati, W. (2016) 'Hubungan Pengetahuan dengan Perilaku Ibu Memberikan
Pendidikan Seks pada Anak', Universitas Sebelas Maret.

Wong D. L., W. (2013) Buku Ajar Keperawatan Pediatrik, Alih bahasa Sunarno, Agus dkk. 6th edn. Jakarta: EGC. 
